\title{
Humic substances and significance of their application - a review
}

\author{
Aneta Kłeczek \\ aneta.kleczek@pk.edu.pl (iD https://orcid.org/0000-0001-8129-5151
}

\author{
Anna M. Anielak \\ anna.anielak@pk.edu.pl iD https://orcid.org/0000-0001-8965-936X \\ Department of Environmental Technologies, Faculty of Environmental and Power \\ Engineering, Cracow University of Technology
}

Scientific Editor: Michał Zielina, Cracow University of Technology

Technical Editor: Aleksandra Urzędowska, Cracow University of Technology Press Language Verification: Timothy Churcher, Merlin Language Services

Typesetting: Anna Basista, Cracow

University of Technology Press

Received: January 20, 2021

Accepted: July 21, 2021

Copyright: @ 2021 Kteczek, Anielak. This is an open access article distributed under the terms of the Creative Commons Attribution License, which permits unrestricted use, distribution, and reproduction in any medium, provided the original author and source are credited.

Data Availability Statement: All relevant data are within the paper and its Supporting Information files.

Competing interests: The authors have declared that no competing interests exist.

Citation: Kteczek, A., Anielak, A.M. (2021). Humic substances and significance of their application - a review. Technical Transactions: e2021012. https://doi. org/10.37705/TechTrans/e2021012

\begin{abstract}
This paper is based on recent articles regarding applications of humic substances (HSs). HSs are natural organic materials, which have a number of potential applications. Furthermore, HSs are cheap, widespread and obtainable from bio-waste materials. HSs can be used as organic compound sorbents or in detoxification. They are applied as organic additives due to their positive effect on soil and plants, even under stress conditions. HSs reduce water consumption and minimise environmental problems. HSs are utilised for the remediation of multi-metal contaminated soils and as substitutes for synthetic washing agents. From an environmental engineering point of view, it is beneficial to remove HSs from municipal management, where they are undesirable (by-products of disinfection) and to utilise them where they are valuable. The aim of this article is to provide a greater insight into research about the applications of HSs.
\end{abstract}

Keywords: humic substances, humic acids, fulvic acid, humic acid, environmental engineering 


\section{Introduction}

Humic substances (HSs) are naturally occurring, complex and heterogeneous mixtures of polydisperse organic compounds. HSs are formed as a result of humification, which is the second largest organic process on Earth (after photosynthesis) (Weber, 2020; IHSS, 2020). This process involves biochemical and chemical reactions occurring during the decay and transformation of plant and microbial remains. These substances have a relatively high molecular weight and are a variety of shades ranging from yellow to black (Sharma and Anthal, 2016). There are three main fractions of HSs (Dou, Shan, Song, Cao, Wu, Li and Guan, 2020; Gao, Tan, Zhao, Wu, Sun, Qi and Wei, 2019): fulvic acid (FA) - soluble in water at all pH values; humic acid (HA) - insoluble in water under strongly acidic conditions $(\mathrm{pH}<2)$ but soluble at higher $\mathrm{pH}$ values; hymatomelanic acid (HY) - fraction of HA which is soluble in alcohol and humin (HU) - the HSs fraction insoluble in water (Sharma and Anthal, 2016). FA and HA are collectively called humic acids (HAs).

HSs are present in terrestrial and aquatic environments in such components as soil, water and geological organic deposits, which include sediments accumulated on the bottom of lakes (sapropel), leonardite, peat and brown coal (especially low quality coal). Moreover, an important source of HSs is municipal waste management - they are present in raw and treated wastewater, activated sludge, landfill leachate and digested sludge (Anielak, 2019). Currently, there is an interest in obtaining HSs from other materials rich in organic compounds, such as compost and other stabilised bio-waste (which, unlike compost, has no further use). HSs extracted from wastewater, sludge or waste should be investigated with regard to their environmental behaviour, especially the content of metals and other undesirable compounds (Zingaretti, Lieto, Lombardi and Gavasci, 2020).

A number of features reinforce the application of HSs in various industries: agriculture, aquaculture, environmental protection and engineering, medicine, ecological restoration and animal husbandry (Gong, Yuan, Zhang, Li, Liu, Wang, Zhao and Xu, 2020). The properties and structure of HSs depend on their origin and conditions of extraction; however, the average properties of HSs samples from different sources are remarkably similar (Weber, 2020). One of the most important features is sorption capacity - due to the structure of HSs, they are able to bind not only metal cations but also sorb organic compounds. The aromatic nature of HSs makes them effective binders for some persistent organic pollutants (POPs), for example, polycyclic aromatic hydrocarbons (PAHs). Some pesticides constitute another group of organic compounds that can be bound by humic acids (Chianese, Fenti, Iovino, Musmarra and Salvestrini, 2020).

HSs affect soil properties, both physical and chemical, and they also improve its fertility. The addition of these substances improves soil properties like permeability and water retention capacity, and they stimulate root-system development, which affects the enzyme activity and increases the intake of nutrients (Yang, Antonietti, 2020). If soils are regarded as the "skin" of the Earth, HSs should be considered as the "protein" component of the skin (Dou et. al., 2020).

The dark colour of these substances increases the absorption of sunlight, which improves the thermal properties of soils. The soil structure changes due to the addition of humic substances, HS-soil aggregates are formed. Moreover, the water capacity is increased and the maintenance of a specific soil $\mathrm{pH}$ is supported by the presence of HSs (buffer properties). HAs stimulate the growth of roots and leaf shoots and they improve the quantity and quality of crops (Hassan, McInroy and Kloepper, 2019). For example, HAs extracted from leonardite have the potential to modify soil and have beneficial effects on the growth of the green bean plant (Qian, Ding, Li, Liu, Sun and Ding, 2015).

The addition of HSs to poor-quality soils limits the need for irrigation and the use of fertilizers. HSs, as a carbon additive, may contribute to improving the problem of carbon dioxide emissions because they have a negative carbon 
footprint. Moreover, these substances can be obtained from bio-waste, they are cheap and sustainable (Yang and Antonietti, 2020).

HSs can sorb or desorb cations, so they are responsible for their release into the environment and they influence the biological transformation of organic pollutants in water and soil. For example, tests conducted on leachate from landfills have shown that metals present in leachate react with fulvic acids, as a result of which, macromolecular complexes are formed (Huculak-Mączka, Braun-Giwerska, Nieweś, Mulica, Hoffman and Hoffman, 2018; Anielak, 2019).

HSs are highly chemically reactive, but in general they are recalcitrant with respect to biodegradation (IHSS, 2020). However, studies indicate that both HAs and humin can enhance the biodegradation of organic pollutants; moreover, some research results have shown that these substances can be degraded by aerobic and also anaerobic bacteria. Due to these properties, future research about HSs as a prospective material for use in aerobic and anaerobic wastewater treatment and bioremediation has been suggested (Lipczyńska-Kochany, 2018).

A complex formation with HSs is used in drug delivery systems as a carrier agent to increase the bioactivity of natural products. Complexes with HAs improve the solubility of a given factor, thus increasing its effectiveness (Kala, Prashob and Chandramohanakumar, 2019; Khan, Jain, Aqil, Agarwal, Mirza and Iqbal, 2020). For example, the inclusion of complexes with FA extracted from peat positively influence the solubility of ketoconazole, similar results have been obtained for an FA and aspirin formulation, which helps to overcome the problem of the stability and bioavailability of aspirin. Moreover, it gives better results of antiulcerogenic action in comparison to the pure drug (Kala, Prashob and Chandramohanakumar, 2019; Anwer, Ahmed, Ansari and Khan, 2013). One of the factors enabling complexation is the functional groups and their distribution in the structure of the HSs. These substances can be combined with a mineral portion of soil as salts of low-molecular organic acids, salts of HSs with alkaline cations, e.g. $\mathrm{Mg}^{2+}, \mathrm{Ca}^{2+}, \mathrm{Fe}^{2+}$ and $\mathrm{Fe}^{3+}$ - humate (salts of humic acid), fulvate (salts of fulvic acid), chelates with metal ions or as organo-clay compounds. The possibility of the formation of humic chelate complexes is important in the process of regulating the biological availability of metal ions (Weber, 2020). Obtaining HAs for pharmaceutical purposes is justified by their effectiveness, their wide and rich occurrence and the level of safety, as they are already used in dietary supplements (Khan et. al., 2020; Kala, Prashob and Chandramohanakumar, 2019).

The sorption properties and ion exchange capacity of HSs point to the possibility of using them to reduce soil salinity (limiting the concentration of $\mathrm{Cl}^{-}$and $\mathrm{NO}_{3}{ }^{-}$), improve the efficiency of fertilisation (stabilisation of minerals, preventing flushing of groundwater) and detoxification. The immobilisation of heavy metals by HSs reduces the bioavailability of metals to plants - it is similar in the process of removing heavy metals from wastewater, where HAs are used (Yang and Antonietti, 2020).

Using an excessive amount of HAs lead to the inhibition of plant growth and reproduction due to high osmotic pressure. This effect results from the acidic nature of the substances and their solubility - a reaction that is too acidic inhibits the proliferation of microorganisms (e.g. actinomycetes), thus reducing their content and the activity of enzymes in the soil (Yang and Antonietti, 2020).

Another important aspect is that HSs impede the wastewater treatment process and are precursors of organochlorine substances, which are by-products of the disinfection stage of water treatment. It is beneficial to remove these substances from sources where they are undesirable (municipal management) and use them where they can improve the technology of various processes (Anielak, 2019).

This review summaries the newest information regarding the research about the possible applications of humic substances in various fields, such as industry, environment engineering and agriculture. 


\section{Case studies}

In this article, a few selected possibilities of using humic substances are considered. The reviewed data comes from the last two years. Examples of the growing amount of research that determine the influence of HSs on the conditions of plant growth and development are presented, including under stress conditions. The importance of minimising environmental problems using these natural materials was noted, including reducing water consumption and improving the condition of brownfields. The article presents examples of the industrial use of HSs as a sorbent for organic compounds (including pesticides) and as a reagent during leaching processes. Factors supporting the choice of humic substances are their ease of obtaining, their price and their properties. It is important to further develop the knowledge of these substances, which is why this review has been created.

\section{Industrial applications of humic substances}

The potential use of HAs for industrial purposes may lie in their ability to increase the toughness and plasticity of various materials. HAs can replace fossil-based cement additives as well as lignin. The possibility of using HAs in the processes of crystal morphosynthesis, non-classical crystallisation as well as mineralisation and remineralisation in soil is also expected due to the very strong metal ion binding properties of HAs (Yang and Antonietti, 2020).

\subsection{The utilisation of HAs obtained from the wastewater of the olive mill oil industry}

In an experiment in which HA extraction was preceded by abiotic catalysis, the content of the obtained acids in the wastewater tripled in comparison with treatment in open-air lagoon. This indicated the ability of manganese (IV) oxide to efficiently catalyse the organic matter humification process in wastewater from an olive-oil mill. The results were applied industrially in wastewater - abiotic catalysis was applied before the addition of the liquid amendments to induce humification. Enhancing the quality of the HA-like fraction, which is a natural source of organic matter, as a liquid soil amendment is a promising treatment to avoid its dispersion and as a result, to minimise its negative environmental impact. This treatment is especially desirable in semi-arid regions (Brunetti, Sensesi and Plaza, 2008).

\subsection{Humic substances as organic compounds sorbents}

According to current knowledge, sorbing efficiency is strongly related to the hydrophobicity of the sorbate. HAs are potential green materials that can be used in water and wastewater treatment processes. Interactions of HAs with organics result from $\pi-\pi$ bonds, the hydrophobic effect and hydrogen bonding. To remove organic impurities, HAs are used in three configurations: dissolved in solution, acids in the solid state or immobilised on solid materials. Many studies show that composites containing HAs are often chosen to remove organic pollutants from wastewater (Chianese, Fenti, Iovino, Musmarra and Salvestrini, 2020).

\subsection{Gold leaching with humic substances}

Ecological requirements determine the need for changes in gold hydrometallurgy, including finding new reagents that effectively extract gold from subsoil. Humic substances (also modified) may be a response to the need for a new raw material and may become the basis for new dressing technologies. HSs have complex abilities, are easy to obtain and are non-toxic. In many parameters, they are 
similar to graphene oxide, and they have significant capabilities for modification (Zashikhina and Sviridovaa, 2019).

The gold used in the study was obtained from an alloy of gold and lead. HAs in a solid form used for research was extracted from brown coal deposits located in the area of the former Berezovsk gold mine in Russia. HAs were modified using a cyanide-containing reagent for gold leaching. Modification made it possible to obtain a low-toxic complex with a low cyanide content, and at the same time, the leaching efficiency was very high - the content of dissolved gold in the pregnant solution increased from $14 \mathrm{mg} / \mathrm{l}$ to $30 \mathrm{mg} / \mathrm{l}$. During the process of gold leaching with a solution of ammonia-containing HAs, it has been observed that most of the dissolved gold passes into the precipitate. The remaining and unbound part of the metal is a transition form that does not precipitate, even at $\mathrm{pH} 2$, and remains in the supernatant solution. This indicates the presence of two forms of the dissolved gold (bound and unbound with HAs). The results show that gold forms complexes mainly with the acid fraction isolated by centrifugation in the $\mathrm{pH}$ range of 5.6-4.6. According to the research, HAs are catalysts during the dissolution process as a source of micro impurities (Zashikhina and Sviridovaa, 2019).

\section{HSs applications in environmental engineering}

\subsection{Remediation of soils contaminated with heavy metals - cadmium and arsenic}

Due to the high content of functional groups containing oxygen, HSs are an effective material used for the remediation of soils contaminated with heavy metals. Examples of such metals are $\mathrm{Cd}$ and As, the difficulty of their simultaneous removal is caused by the opposite chemical behaviours of these elements. It is important to adjust the washing conditions to the soil properties. Important factors are the $\mathrm{pH}$ value, the duration and cycles of washing and the HSs concentration (Bi, Yuan, Wei, Xiao, Feng, Meng and Wang, 2019).

The content of $\mathrm{Cd}$ and $\mathrm{As}$ in soil can be a serious problem in specific places, as is the case in China. A national survey showed that the national standards were exceeded in $7 \%$ and $2.7 \%$ of the sampling sites for $C d$ and As, respectively. $\mathrm{Cd}$ and As are toxic and carcinogenic elements - their presence in soil poses a threat to the quality of the environment and human health and has a negative effect on food. Therefore, it is so important to minimise the risk by removing these elements from the soil (Bi et. al., 2019).

The research concerns the possibility of using HSs as a washing agent for the simultaneous removal of $\mathrm{Cd}$ and As from soil. Dissolved HSs were extracted from leonardite. The efficiency of $\mathrm{Cd}$ and As removal with HSs were tested in three types of contaminated soils: red soil, black soil and fluvo-aquic soil. Toxic elements were removed as a result of the complexation of $\mathrm{Cd}$ and $\mathrm{As}$ with the carboxyl and phenolic groups of HSs. The use of HSs as a washing agent is justified due to their efficiency, cheap availability (coal, peat, sludge) and their positive influence on the physical, chemical and biological properties of the soil (Bi et. al., 2019).

Single washing with HSs for twelve hours at $\mathrm{pH} 7$ resulted in the removal of $88.1 \%$ of $\mathrm{Cd}$ and $44.2 \%$ of As from the red soil. The content of $\mathrm{Cd}$ decreased by $75.1 \%$ and As decreased by $57.4 \%$ in fluvo-aquic soil - washing was performed for twelve hours. The effect of a single six-hour wash of black soil reduced the $\mathrm{Cd}$ content by $68.2 \%$, while the As content decreased by $49.9 \%$. Repeated washing resulted in an increased efficiency of toxic-element removal. The $\mathrm{pH}$ value of HSs was close to neutral, positively influencing the removal rate and limiting the possible destructive effect on the soil. The high removal efficiency of $\mathrm{Cd}$ and As from soils and the low content of other metals (Cd: 0.09, Pb: 5.32, Cu: 8.72, Cr: 6.60, As: 3.69 , Ni: $8.39, \mathrm{Zn}: 20.36 \mathrm{mg} / \mathrm{kg}$ ) confirm the applicability of using HSs for the remediation of contaminated soil (Bi et. al., 2019). 


\subsection{Remediation of soils contaminated with heavy metals - copper and lead}

Another study investigated the ability of dissolved HSs extracted from leonardite to mobilise $\mathrm{Cu}$ and $\mathrm{Pb}$ from multi-metal contaminated soils. Soil samples were collected in Romania (Damien, Micle and Sur, 2019).

As a result of the single-stage extraction process, $\mathrm{Cu}$ and $\mathrm{Pb}$ were obtained from the soil. The contaminated soil was mixed with $2 \%$ and $5 \%$ humic solutions at $\mathrm{pH} 9.6$ for different time intervals. The content of $\mathrm{Cu}$ and $\mathrm{Pb}$ in the supernatants and soil samples were measured using atomic absorption spectrometry (AAS) (Damien, Micle and Sur, 2019).

The mobilisation of $\mathrm{Cu}$ and $\mathrm{Pb}$ from contaminated soil is strongly dependent on the stirring time, the soil solution ratio and the concentration of the humic solution used for washing. The results of the research indicate that dissolved HSs obtained from leonardite are effective as a washing agent for soils contaminated with $\mathrm{Cu}, \mathrm{Pb}$ and other highly concentrated pollutants. It is possible to replace synthetic agents such as $\mathrm{Na}_{3}$ EDDS, $\mathrm{HCl}$ and $\mathrm{KMnO}_{4}$ with naturally occurring HSs and chitosan. Change like this is good for the environment because HSs are the main component of soil organic matter; moreover, it is an economically viable substitute. It is important to be aware that the washing effect is sitespecific and depends on specific soil constituents. Acidity-alkalinity conditions have a significant impact on the success of this process - if the soil pH is very low, the ability of HSs to bind heavy metals decreases or even disappears. If the described method is used, the ability to bind metals by HSs in the case of alkaline soils increases (Damien, Micle and Sur, 2019).

The experiment compared the properties of different washing agents for $\mathrm{Cu}$ and $\mathrm{Pb}$ removal from multi-metal contaminated soils. Based on the results, it is observed that the extraction efficiency for $\mathrm{Cu}$ decreased in the order HSs > chitosan $>\mathrm{HCl}>$ distilled water, while for $\mathrm{Pb}$ it was chitosan $>\mathrm{HSs}>\mathrm{HCl}>$ distilled water (Damien, Micle and Sur, 2019).

The low efficiency of $\mathrm{HCl}$ could result from the use of a low concentration of the agent, but otherwise, the concentration value could adversely affect the soil, damaging its physical, chemical and biological structure, and consequently causing the loss of a significant amount of nutrients. The high acidity of the washing agent causes corrosion of the soil and the equipment; in addition, the low $\mathrm{pH}$ of the final solution requires neutralisation, which increases remediation costs. Due to possible secondary contamination and other negative effects, a strong acid is an unsuitable eluent (Damien, Micle and Sur, 2019).

\section{Agriculture applications}

\subsection{Application of humic acids in agriculture}

One of the technologies of organic waste management is composting, which promotes humification and the creation of forms that are more stable than raw waste. Compost can be used as a soil amendment. In agricultural and horticultural production, compost can be a high-quality substitute for peat, which is used for container-grown plants. Municipal solid waste can also be composted - composting reduces the volume and weight of waste by half, and the resulting product can be beneficial for agriculture use. In the tested compost made of municipal solid waste, the maturity of the compost was assessed. It was observed that after 112 days, the HA content of the compost increased to a maximum plateau. Moreover, the cucumber bioassay of compost maturity showed that the highest dry weight of the plants was obtained in the mentioned time (Olk, Bloom, Perdue, McKnight, Chen, Farenhorst, Senesi, Chin, Schmitt-Kopplin, Hertkorn and Harir, 2019; Chefetz, Hatcher, Hadar and Chen, 1996). 
Lignite is a low-rank coal, and instead of being used for energy purposes, it can be implemented in agriculture. Lignite is a source of HSs and may therefore be used as an indirect component of fertilisers. Research was performed in which the properties of HAs obtained from lignite were assessed. The obtained HAs have a high number of aliphatic connections (58-78\%) and a low aromatic polycondensation. Aromatic and aliphatic groups are an important element of the ion exchange capacity, mineral-organic connections with commercial humic products are possible thanks to these groups. Moreover, aromatic structures stabilise organic substances and constitute a source of energy and matter for microorganisms (Huculak-Mączka, Hoffman and Hoffman, 2018).

Each industrial use of HSs is preceded by detailed analyses performed in order to properly characterise them. Depending on the source of HSs and the applied extractants, their structure and properties may differ (Huculak-Mączka, Hoffman and Hoffman, 2018).

\subsection{Stress conditions and humic substances}

The problem of salinity is increasing with the progress of climate change, affecting more and more areas. It is estimated that by 2050 , as much as half of the arable land will be saline. Most crops are sensitive to high salt concentrations in the soil, therefore salinity is considered to be one of the most significant limiting factors with regard to crop yield. In the early phase, salinity reduces soil productivity and has a negative effect on plants, in subsequent stages, the effect also extends to soil organisms, and the soil can become barren as a result. The uptake of nutrients by plants is closely related to the availability of water; when the salinity of the soil increases, the uptake of nutrients by plants is significantly impeded. An example of this is research on wheat in which it was observed that salinity causes the accumulation of sodium ions and a decrease in the potassium content in the shoots and roots. The excessive accumulation of selected chlorine, sodium or magnesium ions is toxic to plants and promotes an imbalance in plant nutrient metabolism (Negm and Abu-Hashim, 2019).

The purpose of the remediation of saline soil is to improve plant resistance and yield; this can be achieved by adding HSs. These substances are characterised by their high cation exchange capacity, which translates into the increased availability of nutrients for plants, and their presence increases the content of organic matter in soil. Moreover, the presence of HA increases soil efficiency as a result of an increased amount of microorganisms and a lower soil $\mathrm{pH}$. In the case of gerbera plants, the addition of HA had a positive effect on plant growth, the number of flowers and the content of N, P, K, Ca, Fe and $\mathrm{Zn}$ in the leaves. In research on tomatoes, it was observed that as a result of applying HA to saline soil, there was an increase in the size of the plant itself, the seed germination rate and the content of micro- and macroelements (Negm and Abu-Hashim, 2019; Yildiztekin, Tuna and Kaya, 2018).

In the experiment, $75 \%$ of the recommended dose of potassium fertiliser covered with HSs was used. The results of the experiment were comparable to those with a full dose, and there was even a positive effect on the quality of the tomatoes grown. Thus, it can be concluded that thanks to the addition of HSs, a higher yield was obtained and pollution was decreased by reducing the amount of fertiliser used (Khan, Ahmed, Ahmed, Khan, Khan, Hussain, Hayat and Sarwar, 2019).

An experiment was conducted in which HSs and Moringa oleifera leaves extract was used to relieve salt stress on wheat. Soils of different salinity levels were collected at three locations near Alexandria, Egypt. The tested samples were fertilised and enriched with HSs. The fertilisers applied to the soil samples are compounds of nitrogen (ammonium sulphate), phosphorus (ordinary superphosphate) and potassium (potassium sulphate). HA in the form of potassium humate and FA as potassium fulvate were mixed and then applied to the soil. Some samples were treated with a foliar spray of Moringa oleifera leaf extract (Negm and Abu-Hashim, 2019). 
The concentration of proline, an the total levels of nitrogen, potassium and phosphorus was determined in selected plants. In grains, the protein percentage was calculated, which is an indicator of the yield quality. At the end of the experiment, soil samples were measured for $\mathrm{pH}$, electrical conductivity (PEW) and organic matter content (Negm and Abu-Hashim, 2019).

The results of the experiment showed that the best qualitative parameters and productivity were obtained when combined HAs (HA and FA) were added to the spray of the extract from Morniga leaves. In terms of effectiveness, HSs can be arranged in descending order: HAs > HA > FA. At all salinity levels, there was observed an increase in straw and grain yield, biological yield and protein content, grain weight and $\mathrm{N}, \mathrm{K}$ and $\mathrm{P}$ uptake by plants, compared to the control soil. Percentage increases of the available forms of elements are from $9 \%$ to $29 \%$ for nitrogen, from $18 \%$ to $45 \%$ for phosphorus and $6-20 \%$ for potassium. There has been research proving that the use of HAs mixed with phosphorus fertiliser leads to the highest content of water-soluble phosphates, increased phosphorus uptake by plants and a significant delay in the formation of phosphate forms unavailable to plants (Negm and Abu-Hashim, 2019).

The addition of HAs and foliar sprays of Moringa leaf extract increased the height of wheat, and the content of chlorophyll a, chlorophyll b, carotenoids and proline. The use of HSs decreased the PEW value of the soil at all tested salinity levels and the amount of organic matter increased in comparison to the control soil (Negm and Abu-Hashim, 2019).

In a different experiment, Capsicum annum L. pepper plants were periodically subjected to salt stress, and the negative effect of salinity on plant parameters was confirmed. After a specified time, HA and seaweed Ascophyllum Nodosum were applied to the tested samples, which improved plant growth and the fresh and dry weight of leaves at various salt concentrations in comparison with control plants. In addition, it was observed that the highest levels of antioxidant enzyme activity (SOD, POD and CAT) in pepper plant leaves occur in the case of salt stress and by the addition of combined HA and seaweed extract. This may mean that the added ingredients increase the plant's stress resistance. Similar results were obtained for rosemary and tomatoes plants (Yildiztekin, Tuna and Kaya, 2018).

The results confirmed the beneficial effect of HAs on the growth, availability and uptake of nutrients by plants under salt stress. Further research is necessary, especially under field conditions, to explain the influence of HAs on the mechanisms of stress alleviation in plants (Negm and Abu-Hashim, 2019).

Apart from salinity, drought is another factor limiting plant growth and development. As a result of water deficiency in plants, reactive oxygen species increase, which leads to an increase in the activity of antioxidant enzymes and peroxidation of lipids, proteins and nucleic acids. Studies conducted for maize, wheat and rape growing under drought conditions verify that foliar application of HA activated the antioxidant enzymatic defence systems in plants, mitigating the effects of reactive oxygen species (ROS). An increase in the content of photosynthetic pigments was also observed (Rombel-Bryzek and Pisarek, 2017).

An experiment was performed on the effect of the foliar application of HA on the leaves of sugar beet plants growing under drought conditions. Plants were divided into three groups - the first group consisted of plants grown under optimal conditions of irrigation, the second group were plants growing under drought conditions; however, similarly to the first case, they were sprinkled with water, the last group were plants growing under drought conditions and foliar sprinkled with a solution of HA (Rombel-Bryzek and Pisarek, 2017).

The specific activity of guaiacol peroxidase (GPOX), the degree of lipid peroxidation in the form of the concentration of malondialdehyde (MDA) and the content of chlorophyll $\mathrm{a}$ and $\mathrm{b}$ were determined in the studied sugar beet plants (Rombel-Bryzek and Pisarek, 2017).

The obtained results showed that the cultivation conditions did not influence the content of chlorophyll $a$ and $b$ in the tested plants. The activity of GPOX was increased in sugar beet growing under drought conditions. The addition of HA to 
these plants did not increase the activity of GPOX in comparison to the plants watered regularly - it led to the inhibition of the plant's antioxidant defence mechanisms. As a result, sugar beet shoots from the third group of the studied plants were characterised by a significant increase in MDA concentration, which indicates an increased effect of the membrane lipid peroxidation process (Rombel-Bryzek and Pisarek, 2017).

The peroxidation process is based on the oxidation of lipid compounds in plant cells. The course and pace of this process are influenced by factors such as the amount of oxygen, the temperature, and the light- and heavy-metal content. The HA used in the experiment were complexed with heavy metals. This resulted in the occurrence of reactions accompanied by the formation of very reactive free radicals, which as a result of interaction with other free radicals, create nonradical products of lipid oxidation (Rombel-Bryzek and Pisarek, 2017).

The HA fraction used during the experiment negatively influenced the physiological processes of sugar beet growing under conditions of drought. HA can contain large amounts of radical scavengers, which means that they can easily interact with free radicals and reduce their content. This property may be important during the formation of the decomposition processes of organic substances in the soil and promote the acquisition of specific HSs fractions which contribute to the increase of resistance caused by biotic and abiotic stress (Rombel-Bryzek and Pisarek, 2017).

Various environmental conditions, including low water availability, salt stress, nutrient deficiency, temperature fluctuations and high irradiances, are particularly undesirable in sandy soils. The combination of these factors affects the deterioration of the retention capacity of the soil and results in a poor yield that is of low quality. Plants that are affected by low temperature and that grow in sandy soils are exposed to biochemical and physiological dysfunctions, which leads to a reduction in their growth rate and a deterioration of the yield quality (Dawood, Abdel-Baky, El-Awadi and Bakhoum, 2019; Zhou, Monreal, McLaughlin, Zhang, Hao and Liu, 2019).

In Egypt, an experiment was performed on the effect of foliar spraying under field conditions on the parameters of faba bean plants (Vicia faba L.). The duration of the experiment covered two consecutive winter seasons. Plants grew under sandy soil conditions. The foliar substances used were nicotinamide and HA solutions, which were applied individually or in combination after fortyfive and sixty days of sowing the seeds. At the same time, a control group was prepared - distilled water was used as a spray every five days (Dawood, AbdelBaky, El-Awadi and Bakhoum, 2019).

The results showed that the addition of nicotinamide and HA positively influenced the fresh and dry weight of the plant, the growth of shoot height and the number of roots and leaves. HA affects respiration processes, and the amount of accumulated sugars, amino acids and nitrates. The use of a $5 \%$ solution of HA improved the growth parameters, positively influenced the content of photosynthetic pigments (chlorophyll a, chlorophyll b, carotenoids), the quality and quantity of the yield, as well as selected biochemical components derived from faba bean seeds, such as total phenols, proline, free total amino acids and carbohydrates. The best values of individual parameters compared to the control group were obtained for the application of both nicotinamide and HA (Dawood, Abdel-Baky, El-Awadi and Bakhoum, 2019).

In other research, the effect of applying a bentonite-HA mixture to degraded sandy soil was assessed. The experiment was conducted in China and was aimed at improving the properties of the soil and, consequently, achieving a higher yield of maize (Zea mays L.) cultivation. It was shown that the addition of a bentoniteHA mixture had a positive effect on soil structure, enabling the rapid formation of macro-aggregates, a reduced value of the soil bulk density and an increase in water-storage capacity in the upper layer of soil $(100 \mathrm{~cm})$ were also seen. The application of the bentonite-HA mixture contributed to the increase in yield, the growth of the maize plant and to the improvement of water use efficiency by 
$50 \%$ over the five years following the application of the mixture. The use of the described mixture is one of the technologies for reclaiming degraded sandy soils, which is a significant problem in some regions of the world (Zhou et. al., 2019).

\subsection{Humic acids as growth stimulators}

During the research work, the influence of various fractions of HAs extracted from leonardite on seedlings of snap bean (Phaseolus vulgaris L.) was analyzed. The obtained HAs were divided into three groups in terms of molecular weight (Qian et. al., 2015).

The study confirmed that the use of HAs stimulates plant growth. The acid fraction characterised by low molecular weight had a particularly positive effect on plant height compared to the group of control plants (without the addition of HAs) and the group of plants in which acid fractions of a high molecular weight were applied. The beneficial effects include increasing the number of leaves and the total root length, increasing the leaf and root area of snap beans, and promoting the uptake of nitrates by the roots and their accumulation at leaf level. The potassium content in plants also increased with the decreasing molecular weight of the HAs fractions used. HAs fractions characterised by high molecular weight determined leaf growth and reduced the length and surface of the roots. The amount of phosphorus did not differ significantly between the different groups of the tested plants, which may be related to the property of HSs to form complexes with metals. This may lead to the increased sorption of phosphorus ions, the effect of sorption is stronger than the ability of the roots to uptake this element, which reduces the phosphorus content in the plant (Qian et. al., 2015).

In summary, the improvement of physical parameters (growth of leaves and roots of green beans) can be achieved through the use of HAs fractions of low molecular weight, as shown by the results of the experiment (Qian et. al., 2015).

The stimulating effect of HSs was also demonstrated in an experiment on peppermint (Mentha piperita L.), which was subjected to foliar spraying with HSs, chemical fertilisation (nitrogen and potassium fertilisation) and the addition of Funneliformis mosseae (Shahabivand, Padash, Aghaee, Nasiri and Rezaei, 2018).

As a result of the experiment, an increase in the level of proline was observed in the leaves of plants sprayed with HSs and fertilised. Similar effects occurred in the case of maize leaves, in which HSs was applied as foliar, under different irrigation conditions (Shahabivand, Padash, Aghaee, Nasiri and Rezaei, 2018; Anjum, Wang, Farooq, Xue and Ali, 2011).

It was shown that the addition of HSs improved the photosynthesis process in peppermint plants. Other studies also showed a positive effect of HSs on the chlorophyll content of leaves. One of the studies concerned chrysanthemums with chemical fertilisation and foliar spraying with HA solution - the effects of which were better. A different study was conducted under deficient and optimal water regimes, the chlorophyll content in maize also increased after the foliar application of HSs (Shahabivand, Padash, Aghaee, Nasiri and Rezaei, 2018).

The HSs application influenced the accumulation of soluble proteins, which provides information about the role of HSs in the nitrogen cycle. In addition, a reduction in peppermint plant root colonisation was observed similar to that occurring with green beans, probably due to the increased availability of phosphorus in the soil (Shahabivand, Padash, Aghaee, Nasiri and Rezaei, 2018).

The best results were achieved with the combined use of Funneliformis mosseae and spraying with a HSs solution. These two components can be successfully used in the field as biostimulants for peppermint. Such technological solutions contribute to improving soil health and reducing environmental problems in sustainable agriculture (Shahabivand, Padash, Aghaee, Nasiri and Rezaei, 2018). 


\subsection{Sustainability of monoculture paddy rice}

In the Philippines, long-term field trials have been performed on the cultivation of a paddy rice monoculture (double- and triple-cropped). The results of the research have shown a large decline in yields over the decades due to a decrease in the crop uptake of nitrogen from soil organic matter (SOM), despite the increased amounts of this element in these soils and the continuous uptake of nitrogen fertilisers. Presumably, phenolic lignin residues were accumulated in the HA fractions and soil nitrogen cycling was inhibited in the conditions of soil supersaturation with water during the rice-cultivation season. In order to improve the nitrogen cycling of the soil, alternate wetting and drying cycles were applied, thereby increasing soil aeration and degrading phenolic lignin residues, which can bind soil nitrogen forms. These new crop management treatments were also created to conserve the water. The combination of the described treatments and fertilisation resulted in the amount of water needed for irrigation being reduced by $25 \%$, what is more, a significant decrease in greenhouse gas emissions was also achieved, equal to $90 \%$, the incidence of fungal diseases and the content of arsenic and mercury in grains also decreased (Olk et. al., 2019).

The characterisation of HA extracted without first removing calcium allowed a better understanding of the nitrogen cycle of the soil. Concepts based on these characteristics have contributed to the achievement of sustainable rice production. It has been verified that the fractions of $\mathrm{HA}$ can reflect the dynamics of SOM, thus the obtained information can be used in solving problems related to soil-nutrient cycling (Olk et. al., 2019).

\section{Other applications}

\subsection{Humic water (HW) drinking cure}

HW is a combination of an extract of natural HAs and minerals. Most commonly, it is only a fraction of the HA that is used. These waters are characterised by a low content of calcium, magnesium, sulphates, potassium and metaboric acid. The main cationic component of humic waters is the sodium ion, while the dominant anion is the bicarbonate or chloride ion. Recently, a research program has been launched to confirm the safety and therapeutic effect of supplementing the diet with HW in patients with alcohol-dependent liver dysfunction. The HW used in the study came from the Brączewo intake in Poland (Veryho, Ziótkowski, Czarniecki, Kłopocka, Budzyński, Liebert, Szot, Chojnowski and Ponikowska, 2019).

As a result of the drinking therapy, there was an improvement in the functioning of the gastrointestinal tracts of the participants of the study; there was no adverse changes in the blood count, the level of C-reactive protein (CRP), or the electrolyte changes in the blood serum and biochemical indicators reflecting the function of the liver and kidneys. The effects of using HW were positive and indicated the safety of this method; therefore, it is justified to continue research on using them for people with diseases and disorders of liver function (Veryho et. al., 2019).

\section{Conclusions}

HSs that are cheap and widely used materials and compounds have found applications in many fields and the possibilities of their use is constantly expanding. The physicochemical characteristics of the obtained product should always be characterised in detail so that they meet certain quality standards. The main possibilities of using HSs are as sorbents (detoxification, removal of other organic compounds), as organic modifications in agriculture (foliar spraying, soil remediation) and as substitutes for synthetic agents (washing agent, reagent in leaching processes). 
The important fact is that usage of HSs contributes to improving soil health, reducing water consumption and minimising environmental problems. It enables agricultural activity in a sustainable manner. The use of HSs saves costs, especially when substances are extracted from bio-waste or other sources that have no further use.

Knowledge about these substances should be further developed, especially as long-term and field-based research. Such actions, even without knowing exact chemical structure of HSs, make it possible to determine their influence on environmental elements. The more the information that is obtained, the more precise the identification of the potential uses of these specific substances will be.

\section{References}

Anielak, A. (2019). Kwasy humusowe. Ekstrakcja, analiza i znaczenie w środowisku oraz metody ich usuwania. Przemyst Chemiczny, 1580-1586. http:// doi.org/10.15199/62.2019.10.10

Anjum, S.A., Wang, L., Farooq, M., Xue, L., Ali, S. (2011). Fulvic acid application improves the maize performance under well-watered and drought conditions. Journal of Agronomy and Crop Science, 409-417. http://doi. org/10.1111/j.1439-037X.2011.00483.x

Anwer, M., Ahmed, M., Ansari, M., Khan, T. (2013). Inclusion complex of solid state aspirin with fulvic acid: dissolution, permeability, stability and preliminary pharmacological studies. Journal of Biological Sciences, 302-312. http:// doi.org/10.3923/jbs.2013.302.312

Bi, D., Yuan, G., Wei, J., Xiao, L., Feng, L., Meng, F., Wang, J. (2019). A Soluble Humic Substance for the Simultaneous Removal of Cadmium and Arsenic from Contaminated Soils. International Journal of Environmental Research and Public Health. http://doi.org/10.3390/ijerph16244999

Brunetti, G., Sensesi, N., Plaza, C. (2008). Organic matter humification in olive oil mill wastewater by abiotic catalysis with manganese(IV) oxide. Bioresource Technology, 8528-8531. http://doi.org/10.1016/j.biortech.2008.02.047

Chefetz, B., Hatcher, P.G., Hadar, Y., Chen, Y. (1996). Chemical and biological characterization of organic matter during composting of municipal solid waste. Journal of Environmental Quality, 776-785. http://doi.org/10.2134/ jeq1996.00472425002500040018x

Chianese, S., Fenti, A., Iovino, P., Musmarra, D., Salvestrini, S. (2020). Sorption of Organic Pollutants by Humic Acids: A Review. Molecules. http://doi. org/10.3390/molecules25040918

Damian, G.E., Micle, V., Sur, I.M. (2019). Mobilization of $\mathrm{Cu}$ and Pb from multimetal contaminated soils by dissolved humic substances extracted from leonardite and factors affecting the process. Journal of Soils and Sediments, 2869-2881. http://doi.org/10.1007/s11368-019-02291-w

Dawood, M.G., Abdel-Baky, Y.R., El-Awadi, M.E., Bakhoum, G.S. (2019). Enhancement quality and quantity of faba bean plants grown under sandy soil conditions by nicotinamide and/or humic acid application. Bulletin of the National Research. http://doi.org/10.1186/s42269-019-0067-0

Dou, S., Shan, J., Song, X., Cao, R., Wu, M., Li, C., Guan, S. (2020). Are humic substances soil microbial residues or unique synthesized compounds? A perspective on their distinctiveness. Pedosphere, 159-167. http://doi. org/10.1016/S1002-0160(20)60001-7

Gao, X., Tan, W., Zhao, Y., Wu, J., Sun, Q., Qi, H., Wei, Z. (2019). Diversity in the Mechanisms of Humin Formation during Composting with Different Materials. Environmental Science \& Technology, 3653-3662. http://doi. org/10.1021/acs.est.8b06401 
Gong, G., Yuan, X., Zhang, Y., Li, Y., Liu, W., Wang, M., Zhao, Y., Xu, L. (2020). Characterization of coal-based fulvic acid and the construction of a fulvic acid molecular model. The Royal Society of Chemistry. http://doi. org/10.1039/c9ra09907g

Hassan, M.K., McInroy,J.A., Kloepper,J.W.(2019). The Interactions of Rhizodeposits with Plant Growth-Promoting Rhizobacteria in the Rhizosphere: A Review. Agriculture. http://doi.org/10.3390/agriculture9070142

Huculak-Mączka, M., Braun-Giwerska, D., Nieweś, D., Mulica, M., Hoffman, J., Hoffman, K. (2018). Torf i węgiel brunatny jako surowce do otrzymania kwasów humusowych. Proceedings of ECOpole, 499-505. http://doi. org/10.2429/proc.2018.12(2)049

Huculak-Mączka, M., Hoffman, J., Hoffman, K. (2018). Evaluation of the possibilities of using humic acids obtained from lignite in the production of commercial fertilizers. Journal of Soils and Sediments, 2868-2880. http:// doi.org/10.1007/s11368-017- 1907-x

International Humic Substances Society. Retrieved from: http://humic-substances. org/what-are-humic-substances-2/ (access: 10/10/2020).

Kala, K.J., Prashob, P.K.J., Chandramohanakumar, N. (2019). Humic substances as a potent biomaterials for therapeutic and drug delivery system - review. International Journal of Applied Pharmaceutics. http://doi.org/10.22159/ ijap.2019v11i3.31421

Khan, M.Z., Ahmed, H., Ahmed, S., Khan, A., Khan, R.U., Hussain, F., Hayat, A., Sarwar, S. (2019). Formulation of humic substances coated fertilizer and its use to enhance $\mathrm{K}$ fertilizer use efficiency for tomato under greenhouse conditions. Journal of Plant Nutrition, 626-633. http://doi.org/10.1080/01 904167.2019.1568462

Khan, R., Jain, P., Aqil, M., Agarwal, S.P., Mirza, M.A., Iqbal, Z. (2020). Pharmacokinetic evaluation of fulvic acid-ketoconazole complexes: A validation and line extension study. Journal of Drug Delivery Science and Technology. http://doi.org/10.1016/j.jddst.2019.101469

Lipczynska-Kochany, E. (2018). Humic substances, their microbial interactions and effects on biological transformations of organic pollutants in water and soil: A review. Chemosphere, 420-437. http://doi.org/10.1016/j. chemosphere.2018.03.104

Negm, A., Abu-Hashim, M. (2019). Sustainability of Agricultural Environment in Egypt: Part II. The Handbook of Environmental Chemistry, Merwad, A.M.A. Using Humic Substances and Foliar Spray with Moringa Leaf Extract to Alleviate Salinity Stress on Wheat. Springer, Cham, 265-286. http://doi. org/10.1007/698_2018_298

Olk, D.C., Bloom, P.R., Perdue, E.M., McKnight, D.M., Chen, Y., Farenhorst, A., Senesi, N., Chin, Y.-P., Schmitt-Kopplin, P., Hertkorn, N., Harir, M. (2019). Environmental and Agricultural Relevance of Humic Fractions Extracted by Alkali from Soils and Natural Waters. Journal of Environmental Quality, 217-232. http://doi.org/10.2134/jeq2019.02.0041

Qian, S., Ding, W., Li, Y., Liu, G., Sun, J., Ding, Q. (2015). Characterization of humic acids derived from Leonardite using a solid-state NMR spectroscopy and effects of humic acids on growth and nutrient uptake of snap bean. Chemical Speciation \& Bioavailability, 156-161. http://doi.org/10.1080/0 9542299.2015.1118361

Rombel-Bryzek, A., Pisarek, I. (2017). Wpływ kwasów huminowych na aktywność metaboliczną buraka cukrowego w warunkach suszy. Proceedings of ECOpole, 279-286. http://doi.org/10.2429/proc.2017.11(1)030

Shahabivand, S., Padash, A., Aghaee, A., Nasiri, Y., Rezaei, P.F. (2018). Plant biostimulants (Funneliformis mosseae and humic substances) rather than chemical fertilizer improved biochemical responses in peppermint. Iranian Journal of Plant Physiology, 2333-2344. http://doi.org/10.22034/ ijpp.2018.539109 
Sharma, A., Antha, R. (2016). Humic Substances in Aquatic Ecosystems: A Review. International Journal of Innovative Research in Science, Engineering and Technology, 18462-18470. http://doi.org/10.15680/ IJIRSET.2016.0510051

Veryho, N., Ziółkowski, M., Czarniecki, D., Kłopocka, M., Budzyński, J., Liebert, A., Szot, K., Chojnowski, J., Ponikowska, I. (2019). Wptyw kuracji pitnej wodą humusową na obrazowe i laboratoryjne parametry funkcji wątroby u pacjentów uzależnionych od alkoholu - wyniki wstępne. Hygeia Public Health, 48-55.

Weber, J. (2020). Humic Substances and their Role in the Environment. EC Agriculture, 03-08.

Weber, J. Formation of humic substances. Retrieved from: http://karnet.up.wroc. $\mathrm{pl}$ - weber/powstaw1.htm (access: 18/05/2020).

Yang, F., Antonietti, M. (2020). The sleeping giant: A polymer View on humic matter in synthesis and applications. Progress in Polymer Science. http:// doi.org/10.1016/j.progpolymsci.2019.101182

Yildiztekin, M., Tuna, A.L., Kaya, C. (2018). Physiological effects of the brown seaweed (Ascophyllum nodosum) and humic substances on plant growth, enzyme activities of certain pepper plants grown under salt stress. Acta Biologica Hungarica, 325-335. http://doi.org/10.1556/018.68.2018.3.8

Zashikhina, A.V., Sviridovaa, M.L. (2019). Gold Leaching with Humic Substances. Fiziko-Tekhnicheskie Problemy Razrabotki Poleznykh Iskopaemykh, 151-156. http://doi.org/10.1134/S1062739119046002

Zhou, L., Monreal, C.M., Xu, S., Mclaughlin, N.B., Zhang, H., Hao, G., Liu, J. (2019). Effect of bentonite-humic acid application on the improvement of soil structure and maize yield in a sandy soil of a semi-arid region. Geoderma, 269-280. http://doi.org/10.1016/j.geoderma.2018.12.014

Zingaretti, D., Lieto, A., Lombardi, F., Gavasci, R. (2020). Humic Substances Extracted from a Bio-stabilized Waste Applying Different Operating Conditions. Waste Biomass Valor. http://doi.org/10.1007/s12649-02001085-3 